\title{
The relationship between fear and exploration in rats'
}

\section{DAVID LESTER, Wellesley College, Wellesley, Mass. 02181}

Rats were exposed to an arm of a maze. As the arm was made less enclosed, the rats approached the arm more. Eventually, as the arm was made even less enclosed, the rats approached the arm less. These results support the existence of an inverted $U$-shaped relationship between the fear level of rats and the extent of their exploratory behavior.

Lester (1967a) proposed a theory of exploration in which mild fear facilitates exploration whereas strong fear inhibits exploration. The majority of studies report an inhibitory effect from fear on exploration, but a few do report a facilitatory effect (Lester, 1968a). No experiment has yet found both facilitatory and inhibitory effects.

Lester tried presenting a group of rats with a fear-arousing stimulus repeatedly. Over time, the fear aroused by this stimulus should habituate; thus the exploratory behavior should first be inhibited (when the aroused fear is strong) and then facilitated (when the aroused fear has dropped to a mild level). In one study 2 the fear-arousing stimulus was the bang from a start box door as it opened and in a second study, ${ }^{3}$ the elevated part of a runway. These situations led to an enormous variation in the performance of the rats which increased with repeated testing, obscuring any trends in the data.

In a study of the orderliness of exploration over time in a Y-maze, the orderliness reached a peak during the middle $10 \mathrm{~min}$ of the 20-min period of exploration (Lester, 1968b). If the fear aroused by the maze is assumed to habituate over time, the first $5 \mathrm{~min}$ of the exploratory period illustrates the inhibitory effect of fear on exploration and the middle $10 \mathrm{~min}$ illustrates a facilitatory effect. Lester interpreted this study as illustrating both inhibitory and facilitatory effects from fear on exploration. ${ }^{4}$

In another study, Lester (1968c) correlated the defecation of rats in an open field and their activity. He found that rats that defecated in the open field had extreme activity scores (very low and very high). The author interpreted these results as supporting the existence of a $U$-shaped function between fear and exploration.

The present study sought to test the existence of the U-shaped function in a third way, using an experimental technique. The fear level of different groups of rats was manipulated by presenting them with a runway of varying degrees of openness, since Montgomery (1955) and Lester (1967b) have reported that elevating a runway appears to raise the fear level of rats.

\section{METHOD}

The Ss were 24 female rats of the Charles River Breeding Laboratories, strain $C D$, caged singly with ad lib food and water. They were 98 days old.

The apparatus was a runway with a wood base. Part of the runway had wood walls and was covered with wire mesh. Group A experienced the other part of the runway with two wood walls and a wire-mesh top; Group B experienced it with one wood wall, one wire-mesh wall and a wire-mesh top; Group C experienced it with two wire-mesh walls and a wire-mesh top; and Group D experienced it with no walls or top. The arms of the maze were $18 \times 6 \times 6$ in., located 32 in. from the floor. An electric motor provided masking noise in the experimental room.

On each of Days $1-4$, each rat was placed in the maze for $3 \mathrm{~min}$. The time during which at least the rat's head was in the "fear-arousing" part of the runway was noted to the nearest $0.1 \mathrm{sec}$ with a stop-watch.

\section{RESULTS}

The data were subjected to a two-way analysis of variance for repeated measures (Winer, 1962). (The criterion for homogeneity of variance was met.) The effect of the fear-arousing stimulus was significant $(F=7.76, \mathrm{df}=3 / 20$, $p<0.01)$. The effect of the successive tests was not significant $(\mathrm{F}=1.25, \mathrm{df}=3 / 60)$ and neither was the interaction term $(F=1.32, d f=9 / 60)$. The mean times spent by the rats on the fear-arousing arm are shown in Table 1.

Group B (one wood wall and one wire wall) showed the greatest approach behavior on each of the four days of testing (binomial $p=0.06$ for a comparison of Group B with any of the three other groups; binomial $p=0.004$ for a comparison of all four groups together).

The effect was strongest on Day 1. A median test showed that Groups B and C approached the arm significantly more than Groups $A$ and $D\left(\chi^{2}=13.5\right.$, df $\left.=1, \mathrm{p}<0.001\right)$. On Day 4 this difference was also significant $\left(\chi^{2}=4.2, \mathrm{df}=1\right.$, $p<0.05$ ) and on Days 2 and 3 the difference was in the same direction but did not reach significance $\left(\chi^{2}=1.00, \mathrm{df}=1\right)$. A median test for all four days of testing combined was significant $\left(\chi^{2}=4.2, \mathrm{df}=1, \mathrm{p}<0.05\right)$.

\section{DISCUSSION}

Rats placed on an elevated maze appear to be more emotional than rats placed in an enclosed maze (Lester, 1967b; Montogomery, 1955). In the present experiment, the rats were exposed to parts of a maze that gradually changed from being enclosed to elevated. As the arm changed, the rats first showed an increasing tendency to approach the arm and finally a decreasing tendency. The $U$-shaped function is that predicted by Lester (1967a).

One objection that can be made to the interpretation of this experiment is that the arms of the runway present an increasingly complex stimulus as the arm is made more open which could be a confounding variable with the fear aroused by the stimulus. However, it is not clear that the stimulus array presented by an elevated maze is more complex than that presented by an enclosed maze. We do not know the limits of the rat's perception. Sheldon (1968) has noted that the rat on an elevated maze spends much time with his head over the arm of the maze, but this may result from the absence of a wall to confine the rat rather than visual exploration of the environment.

One final point is that as the arm of the runway is made more open, it becomes lighter, which might discourage the rat

Table 1

The Mean Times (in seconds) spent on the Fear-Arousing Part of the Runway by the Rats

\begin{tabular}{|c|c|c|c|c|c|}
\hline \multirow[b]{2}{*}{ Group } & \multicolumn{4}{|c|}{ Test } & \multirow{2}{*}{$\begin{array}{l}\text { Mean Time Over } \\
\text { All Four Tests }\end{array}$} \\
\hline & 1 & 2 & 3 & 4 & \\
\hline A 2 wood walls & 46.0 & 56.8 & 60.5 & 60.2 & 55.9 \\
\hline $\begin{array}{l}\text { B } 1 \text { wood wall } \\
1 \text { wire wall }\end{array}$ & 70.5 & 62.4 & 65.7 & 69.0 & 66.9 \\
\hline C 2 wire walls & 70.0 & 53.3 & 60.6 & 60.4 & 61.1 \\
\hline D no walls & 44.4 & 35.3 & 38.4 & 40.4 & 39.6 \\
\hline
\end{tabular}

Median test on

Groups B and C vs Groups $A$ and $D$ for each day
$\chi^{2}$
$\mathrm{p}$
1.0

ns $\quad<0.05<0.05$

(Continued on page 130) 
Table 2

Test Scores of Two Sets of Group-Imprinted Mallard Ducklings

\begin{tabular}{lllll}
\hline Duck No. & $\begin{array}{l}\text { Object } \\
\text { Imprinted }\end{array}$ & $\begin{array}{l}\text { Object } \\
\text { Chosen }\end{array}$ & $\begin{array}{l}\text { Latency to Contentment Tone } \\
\text { Reach I ft } \\
\text { of Object }\end{array}$ \\
\hline & & Group A & \\
\hline 1 & Decoy & Decoy & $2 \mathrm{sec}$ & strong, immediate \\
2 & Decoy & Decoy & $1 \mathrm{sec}$ & strong, immediate \\
3 & Decoy & Decoy & $2 \mathrm{sec}$ & strong, immediate \\
4 & Decoy & Decoy & $1 \mathrm{sec}$ & strong, immediate \\
5 & Decoy & Decoy & $1 \mathrm{sec}$ & strong, immediate \\
\hline & & Group B & \\
\hline 6 & Decoy & Decoy & $2 \mathrm{sec}$ & strong, immediate \\
7 & Decoy & Decoy & $1 \mathrm{sec}$ & strong, immediate \\
8 & Decoy & Decoy & $1 \mathrm{sec}$ & strong, immediate \\
9 & Decoy & Decoy & $2 \mathrm{sec}$ & strong, immediate \\
10 & Decoy & Decoy & $1 \mathrm{sec}$ & strong, immediate \\
\hline
\end{tabular}

natural parent during the first day of life. This learning we call "genetically programmed."

\section{EXPERIMENT 2}

Procedure

Ten wild mallard ducklings, . hatched and individually isolated as in Experiment 1, were imprinted to the remote-control decoy at the age of $15-16 \mathrm{~h}$ in the same room and with the same procedure. Five of these ducklings (Group A) were imprinted simultaneously upon the decoy and the other five (Group B) were imprinted in the same way. As in Experiment 1 , the ducklings received 10 additional $1 / 2-h$ imprinting exposures over a period of three weeks.

At the end of the three weeks, the ducklings were individually tested for imprinting, just as in Experiment 1, with the person whose voice had been emitted by the decoy used as the unfamiliar object.

\section{Results}

All 10 ducklings followed the decoy during the initial imprinting experience. In the test situation, all ducklings went immediately to the decoy upon which they had been imprinted, with most ducklings taking only $1 \mathrm{sec}$ or less to be within $1 \mathrm{ft}$ of the decoy; many of them immediately dashed to the decoy. In addition, every duckling emitted strong and immediate contentment tones to the decoy. There was absolutely no difference in the performance of the two groups of group-imprinted ducklings. These data are shown in Table 2.

\section{Discussion}

While in the natural situation ducklings are together in a group during the period that imprinting to the parent takes place, most laboratory experimentation on imprinting has exposed birds individually to the imprinting object, particularly since it is more difficult to observe a number of birds at once. Furthermore, this procedure has been observed as a precaution against the possibility of the young birds imprinting to each other rather than to the model.

While it is certainly true that young chicks and ducklings, as Polt \& Hess $(1964,1966)$ and Hess (1964) have found, imprint to their siblings when a parent object is absent and then can fail to imprint to a parent object even when isolated from siblings, Experiment 2 in comparison with Experiment 1 shows that simultaneous exposure to siblings at the time imprinting to a parent object is taking place does not have any deleterious effect upon that imprinting. Fabricius (1951) noted that while the flocking tendency of naturally reared ducklings is very strong, when being with the parent object conflicts with being with siblings, the former will be chosen. He was, however, erroneously led by this observation to conclude that sibling imprinting does not take place. Once again, the importance of factors present in the natural situation becomes evident; they must be considered if we are to assess correctly the nature of the imprinting process.

\section{REFERENCES}

FABRICIUS, E. Zur Ethologie junger Anatiden. Acta Zool. Fenn., 1951, $68,1-175$

HESS, E. H. Imprinting in birds. Science, 1964, 146, 1128-1139.

LORENZ, K. Z. Der Kumpan in der Umwelt des Vogels. Journal fur Ornithologie, 1935, 83, 137-213, 289-413.

POLT, J. M., \& HESS, E. H. Following and imprinting: Effects of light and social experience. Science, $1964,143,1185-1187$.

POLT, J. M., \& HESS, E. H. Effects of social experience on the following response in chicks. Journal of Comparative \& Physiological Psychology, 1966, 61, 268-270.

NOTE

This research was supported by Grant 776 of the National Institute of Mental-Health and by the Wallace C. and Clara A. Abbott Memorial Fund of the University of Chicago.

\section{(Continued from page 128)}

from approaching the arm. However, this would act against the prediction of the present experiment and so cannot be raised as an objection to the interpretation of the study.

\section{REFERENCES}

LESTER, D. Sex differences in exploration: Toward a theory of exploration. Psy chological Record, 1967a, 17, 55-62.

LESTER, D. Effects of fear on exploratory behavior. Psychonomic Science, 1967b, 9, 117-118.

LESTER, D. The effect of fear and anxiety on exploration and curiosity: Toward a theory of exploration. Journal of General Psychology, 1968a, 79, 105-120.

LESTER, D. The effects of the habituation of fear on the exploratory behavior of rats. Nature, $1968 \mathrm{~b}$, in press.

LESTER, D. Two tests of a fear-motivated theory of exploration. Psychonomic Science, 1968c, 10, 385-386.
MONTGOMERY, K. C. The relation between tear induced by novel stimulation and exploratory drive. Journal of Comparative \&. Phy siological Psychology, 1955, 48, 254-260.

SHELDON, M. H. Exploratory behavior: The inadequacy of activity measures. Psychonomic Science, 1968, 11, 38.

WINER, B. J. Statistical principles in experimental design. New York: McGraw-Hill, 1962.

\section{NOTES}

1. This research was supported by Research Grant MH 14404-01 from the National Institute of Mental Health.

2. Lester, D. Effects of a repeated fear-arousing stimulus on the exploration of rats. Unpublished manuscript, Wellesley College, 1968.

3. Lester, D. Effects of a repeated fear-arousing stimulus on the exploration of rats: A second study. Unpublished study, Wellesley College, 1968

4. The individual variation in performance is minimized here since no handling of the rats takes place between the different segments of the exploratory test. 